\title{
Harlequin Ichthyosis: a rare congenital dermatological disorder
}

\author{
Charu Sharma $^{1 *}$, Tapan K. Bhattacharyya ${ }^{1}$, Abhishek Bhardwaj ${ }^{2}$, Manju Mehrotra ${ }^{3}$
}

\begin{abstract}
${ }^{1}$ Department of Obstetrics \& Gynecology, Andaman \& Nicobar Islands Institute of Medical Sciences, Port Blair, India ${ }^{2}$ Department of Dermatology, Andaman \& Nicobar Islands Institute of Medical Sciences, Port Blair, India

${ }^{3}$ Department of Obstetrics \& Gynecology, Andaman \& Nicobar Islands Institute of Medical Sciences, Port Blair, India
\end{abstract}

Received: 04 October 2015

Accepted: 18 November 2015

\section{*Correspondence:}

Dr. Charu Sharma,

Email: sharma.charu651@gmail.com

Copyright: (c) the author(s), publisher and licensee Medip Academy. This is an open-access article distributed under the terms of the Creative Commons Attribution Non-Commercial License, which permits unrestricted non-commercial use, distribution, and reproduction in any medium, provided the original work is properly cited.

\begin{abstract}
Harlequin Ichthyosis is the most severe form of congenital Ichthyosis presenting at birth. It is a very rare disorder with autosomal recessive inheritance. Perinatal mortality is high and the survivors develop severe erythroderma subsequently. We report a case of Harlequin Ichthyosis not only because of its rarity but also its tendency to occur in consecutive pregnancies.
\end{abstract}

Keywords: Harlequin, Ichthyosis, Skin biopsy, Prenatal diagnosis, Consanguineous

\section{INTRODUCTION}

Harlequin Ichthyosis is the most severe form of congenital Ichthyosis presenting at birth. It is a very rare disorder with autosomal recessive inheritance. ${ }^{1}$ The affected newborn is encased in armor like thick yellow plates of scales with deep red fissuring. The skin is stretched tightly so that the face loses its normal appearance with ectropion, eclabium and flattening of ears and nose. The extremities are swollen due to constriction by massive thickening of the skin. There is a stillbirth or a preterm delivery. Live born infants usually die within the first few days of life from respiratory infections, hypoglycemia or dehydration related disorders. More than 100 cases of Harlequin Ichthyosis have been reported but only few have been reported from India.

\section{CASE REPORT}

A 23 years old multiparous lady presented to our hospital at 36 weeks period of gestation with labor pains. There was history of consanguinity and a sibling death in the early neonatal period in the previous pregnancy. The first baby was told to have an abnormality involving the skin and limbs which was not compatible with life. However the exact diagnosis was not known. During this pregnancy the patient had a regular antenatal check-up with serial ultrasounds showing no gross anomaly. There was no structural or numeric chromosomal abnormality in either of the parents. Patient was non diabetic and her basic antenatal investigations were within normal limits.

The couple was expecting a normal pregnancy this time. The patient was in active labor and was taken up for an emergency caesarean section in view of fetal distress. She 
delivered an alive male baby weighing 2.8 kilograms with an Apgar score of 6 at one minute and 5 at five minutes. The baby was immediately intubated and shifted to neonatal intensive care unit in view of respiratory distress. The baby had hard, fissured hyperkeratotic skin with grossly deformed facial features, eclabium (eversion of lips), ectropion (eversion of lids) and small ears suggesting Harlequin Ichthyosis. Fingers and toes were hypoplastic and constricted. Palmer and plantar creases were not formed (Figure 1, 2). Upper and lower limbs were in a semi flexed position with flexion deformity at elbows and knees causing restricted mobility. The parents and relatives on first sight of the baby revealed that a similar baby was born to them five years back that died within 24 hours.

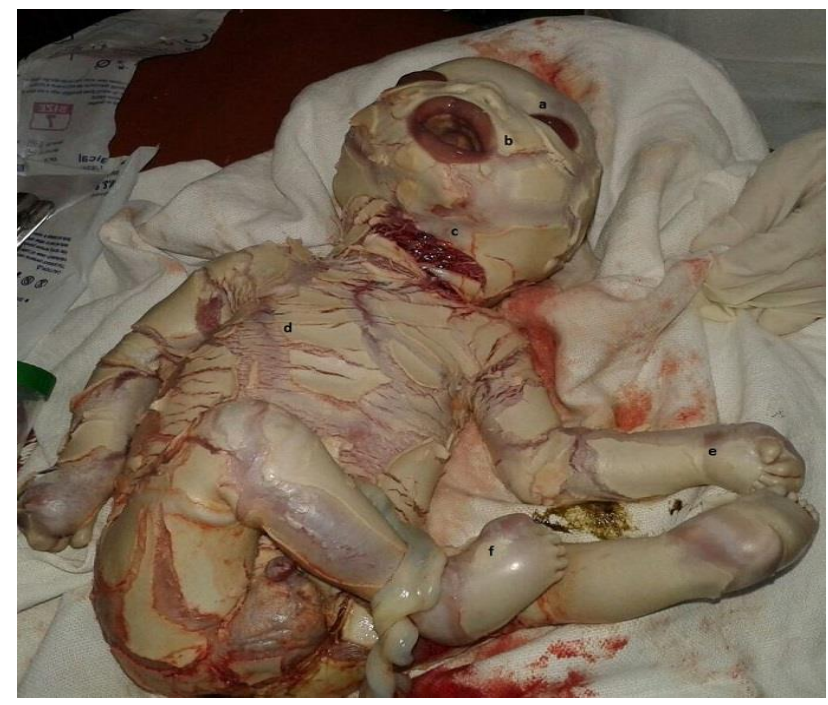

Figure 1: (a) Ectropion; (b) eclabium; (c) erythematous fissure; (d) yellowish plaques; (e) hypoplastic fingers with absent palmar creases; (f) constricted toes.

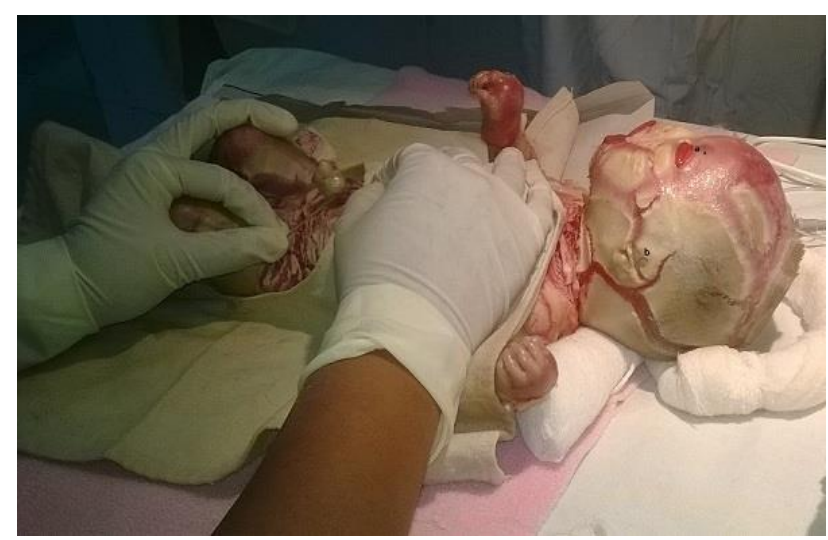

Figure 2: (a) Ectropion; (b) Rudimentary ear.

This baby was nursed in a humidified environment. Umbilical vein catheterization was done for an intravenous access and intravenous fluids and antibiotics were started. Topical care by application of emollients was provided. Baby was fed using nasogastric tube and oxygen was given by oxygen hood. Despite adequate supportive care, baby expired within thirty six hours due to respiratory distress and septicemia. The parents declined autopsy and genetic examination.

\section{DISCUSSION}

Harlequin Ichthyosis is a rare keratinizing disorder. It probably represents several genotypes with similar clinical manifestations and has an incidence of 1 in 3, 00,000 live births. ${ }^{2}$ The first report was made by Oliver Hart, of Charleston, South Carolina, who described some features of this disorder in $1750 .^{3}$ The name 'Harlequin' is derived from the striking resemblance of the skin of

these babies to the costume of the comic servant character 'archetypal Harlequin'. This disorder has been reported in different ethnic groups and in both sexes. No racial predilection is known for Harlequin Ichthyosis. A higher incidence may be encountered in societies where consanguinity is common. ${ }^{4}$ A consanguineous marriage can be characterized by the degree of relatedness between the spouses. Genetic effects of consanguinity can be traced to the fact that the inbred individual may carry two copies of a gene that was present in a single copy in the common ancestor of his/her consanguineous parents. A recessive gene may thus come to light for the first time in an inbred descendant after having remained hidden for generations. ${ }^{5}$ For this reason, consanguinity influences the incidence of some inherited diseases. In our case also, the couple was consanguineous.

Harlequin Ichthyosis is an autosomal recessive disease and there are $25 \%$ chances of recurrence in successive pregnancies. Mutations in the ABCA 12 gene encoding an adenosine triphosphate binding cassette (ABC) transporter are the underlying defect. ABCA 12 protein is a keratinocyte lipid transporter associated with lipid transport in lamellar granules and loss of ABCA 12 function leads to a defective lipid barrier in the stratum corneum. $^{4}$

Since there are $25 \%$ chances of recurrence in future pregnancies, it is a challenge for the obstetricians and the radiologists to enable timely diagnosis. Three dimensional (3D) ultrasonography may show certain features like rudimentary ears, flexion contractures, and floating particles in the amniotic fluid suggestive of Harlequin Ichthyosis. Even if there is no history of $\mathrm{HI}$ in family, features like large and gaping mouth, aplasia of the nose, abnormal limbs, and bulging eyes on 3D scans may help in diagnosis. Two-dimensional ultrasonography can also demonstrate features of harlequin ichthyosis but not until late in the second trimester, when enough keratin buildup is present to be sonographically detectable. Short feet may be an early marker for harlequin ichthyosis. ${ }^{6}$

Apart from imaging, fetal skin biopsy also has a role in prenatal diagnosis. On light microscopy, premature 
keratinization can be identified by 20th to 22 nd week. Electron microscopy may show atypical intraepidermal vesicles at 16 weeks. Amniocentesis at 17 weeks may show intracellular lipid vesicles in clump shed keratinocytes. ${ }^{4}$ DNA-based prenatal testing by direct sequence analysis and restriction enzyme digestion analysis using fetal genomic DNA from amniotic fluid cells at 16 weeks gestation is also available for $\mathrm{HI}$, and it is the investigation of choice for prenatal diagnosis of this condition. Detailed genetic counseling is therefore required for affected families. Extended family members should be advised to avoid consanguineous marriages because of the genetic risk. In our case also, if the diagnosis of previous baby was known, one could have gone for genetic study, intrauterine fetal skin biopsy or at least 3D ultrasonography as 2D scans in the absence of appropriate history may miss the diagnosis.

The mortality rate for Harlequin Ichthyosis is high, with worldwide figures approaching 50\%. However, with neonatal intensive care and oral retinoid therapy (acitretin in the dose of $0.5-1 \mathrm{mg} / \mathrm{kg} /$ day orally), ${ }^{7}$ more babies survive the newborn period than in the past. A topical retinoid (tazarotene) can also be used to treat local and mechanical circulatory problems caused by hyperkeratosis. ${ }^{4}$ In a review of 45 cases by Rajpopat et al it was found that twenty five cases of HI (56\%) survived, ranging in age from 10 months to 25 years and there were twenty deaths $(44 \%)$ from day 1 to day 52 either due to respiratory failure or fulminant sepsis. ${ }^{8}$

Funding: No funding sources Conflict of interest: None declared

Ethical approval: Not required

\section{REFERENCES}

1. Oji V, Tadini G, Akiyama M, Blanchet BC, Bodemer C, Bourrat E. Revised nomenclature and classification of inherited Ichthyosis: results of the First Ichthyosis Consensus Conference in Sorèze 2009. J Am Acad Dermatol. 2010;63(4):607-41.

2. Girish G, Belavadi GB. Harlequin Ichthyosis- A case report. J Pharm Biomed Sci. 2014;04(05):439-42. Available at www.jpbms.info. Accessed 01 October 2015.

3. Waring JI. Early Mention of a Harlequin Fetus in America. Am J Dis Child. 1932;43:442.

4. Prendiville J. Harlequin Ichthyosis. Available at: http//emedicine.medscape.com/article/1111503review. Accessed 30 September 2015.

5. Tayebi N, Yazdani K, Naghshin N. The Prevalence of Congenital Malformations and its Correlation with Consanguineous Marriages. OMJ. 2010;25:37-40.

6. Watson WJ, Mabee LM. Prenatal diagnosis of severe congenital Ichthyosis (harlequin fetus) by ultrasonography. J Ultrasound Med. 1995;14(3):2413.

7. Lacour M, Mehta NB, Atherton DJ, Harper JI. An appraisal of acitretin therapy in children with inherited disorders of keratinisation. Br J Dermatol. 1996;134(6):1023-9.

8. Rajpopat S, Moss C, Mellerio J, Vahlquist A, Gånemo A, Hellstromet M. Harlequin ichthyosis: a review of clinical and molecular findings in 45 cases. Arch Dermatol. 2011;147(6):681-6.

Cite this article as: Sharma C,. Bhattacharyya TK, Bhardwaj A, Mehrotra M. Harlequin Ichthyosis: a rare congenital dermatological disorder. Int J Reprod Contracept Obstet Gynecol 2015;4:2100-2. 